of its excursions in search of pond life, the neighbourhood visited being Totteridge and Mill Hill. Mr. W. Burton obtained two small phials of the water for examination, and the first pipette of water turned out into the trough contained a minute fly, which Mr. Burton kindly brought to me, when I immediately identified it as the Polynema natans (Lubbock, Trans. Linn. Soc., vol. xxiv. I864, p. I35, plate 23).

As this capture was, for the fourth time, the result of chance, Mr. Burton and I set out (May 6) to search for more specimens, After dipping our nets in and carefully examining the contents for over two hours, my patience was at last rewarded by seeing a beautiful female, struggling to free its wings from the mass of minute vegetation gathered in the dipping net. After a few hours more search, I found four males, which, together with the female, I transferred to an observation tank, where all soon disported themselves in the liveliest manner, swimming, or rather flying, under water for over four days, during which period they did no., to my knowledge, once leave the water. I have since obtained others, which are under close observation, and in course of time I hope to trace out their life-history.

Perhaps, owing to the microscopic dimensions of many of the Aymarido (Haliclay), very few entomologists have paid any sttention to this most interesting and fascinating family of beautiful "Fairy Flies," to whose industry we are no doubt largely indebted for our freedom from "blights" of many kinds. They are, indeed, mere specks, scarcely visible to the eyes of ordinary folk, and yet they have their place in nature.

I am inclined to think that when the type collection of the Mymarida, made hy the late Mr. Haliday, has been thoroughly examined, this name Polynema natans will have to give place, so far as the genus is concerned. I hope that before very long we shall have figures of all the genera in this most interesting group. FRED. ENOCK.

\section{Halley's Chart.}

I HAVE been much interested with the letter of Dr. L. A. Bauer in your last number, as I happen to possess a map, or chart, bound up with a number of Dutch, German, and French maps of the end of the seventeenth and the first years of the eighteenth centuries. The latest map with a date is 1704. This English map is evidently the same as 974 (4) mentioned by Dr. Bauer. It is entitled "A new and correct chart showing the Variations of the Compass in the Western and Southern Oceans, as observed in $y^{\mathrm{e}}$ year $\mathrm{I} 700$, by his $\mathrm{Ma}^{\text {ties }}$ command by Edm. Halley." The dedication reads as follows, in Latin: "Majestati semper Auguste Gulielmi III. D.G. Magnæe Britannix Fra. \& Hib. Regis Invictissimi. Tabula hæe Hydrographica Variationum Magneticarum Index. Devotissime Consecratur a Subdito Humillimo Edm. Halley." At one side of the map is the following: "The curve lines which are drawn over the seas in this chart do show at one view all the places where the variation of the compass is the same: The numbers to them show how many degrees the needle declines either Eastwards or Westwards from the true North : and the double line passing near Bermudas and the Cape de Virde isles, is that where the needle stands true without variation."

The chart is in excellent condition, but has no name or printer on it. The only indication is "J. Harris, Sculp." The course of a vessel going from and returning to England is clearly marked.

Northwich, May 27.

THOS. WARD.

\section{ON THE LINE SPECTRA OF THE ELEMENTS.}

I THINK Lecoq de Boisbaudran was the first who called attention to the fact that the line spectra of the elements are by no means so irregular as they seem to be at first sight. He discovered the similarity in the spectra of the alkalies and alkaline earths, and pointed out how the lines in the spectra of these two families seem to be shifted towards the less refrangible side with increasing atomic weight. Mascart, in 1869, found two strong triplets of lines in the ultra-violet spectrum of magnesium, similar to the strong green triplet so prominent in the solar spectrum. He says: "Il semble difficile que la reproduction d'un pareil phénomène soit un effet du hasard; n'est-il pas plus naturel d'admettre que ces groupes des raies semblables sont des harmoniques qui tiennent à la constitution moléculaire du gaz lumineux? Il faudra sans doute un grand nombre d'observations analogues pour découvrir la loi qui régit ces harmoniques." But the wave-lengths corresponding to these rays were then not accurately known, and so the most interesting feature concerning the oscillation frequencies, or the number of waves which pass any fixed point in unit of time, remained unnoticed. It was later on shown by Hartley, that the differences between the wave-numbers of the three lines seem to be the same for all the triplets. This constant difference of wave-numbers repeated in a number of doublets, of triplets, and of more complicated groups of lines, has now been observed in the spectra of many elements. There are repetitions of doublets in the spectra of sodium, potassium, rubidium, cæsium, copper, silver, aluminium, iridium, thallium ; of triplets in the spectra of magnesium, calcium, strontium, zinc, cadmium, mercury, manganese, and of more complicated groups of lines in the spectra of tin, lead, arsenic, antimony, bismuth. In all these cases the differences seem to be absolutely constant. For, notwithstanding the great accuracy with which Rowland has taught us to determine the wave-lengths, the law holds good. As an example, I give the list of doublets in the spectrum of thallium, according to Prof. Kayser's and my determinations. The number of waves passing a fixed point in unit of time, is equal to the distance the light travels in unit of time divided by the wave-length. If we measure the wave-lengths in vacuo, the distance the light travels is the same for all rays. We may then choose as unit of time, the time that light requires to travel one centimetre, so that the wave-number is simply equal to $1 / \lambda, \lambda$ being the wave-length in vacuo, measured in centimetres. In this manner, we get rid of the necessity of settling the velocity of light, which as yet has not been measured with anything like the accuracy with which the wave-lengths are known.

\begin{tabular}{|c|c|c|c|c|c|c|}
\hline${ }^{I / \lambda} \lambda$. & & & Difference. & & & $\begin{array}{l}\text { Estimated } \\
\text { it of error }\end{array}$ \\
\hline $\left.\begin{array}{l}\begin{array}{l}18684^{\circ} \cdot 2 \\
2646^{\circ} 6\end{array}\end{array}\right\}$ & $\cdots$ & $\cdots$ & $7792^{\circ} 4$ & $\cdots$ & $\cdots$ & 0.32 \\
\hline $\left.\begin{array}{l}28324^{\circ} \cdot 1 \\
36 I^{\prime} 7^{\circ}\end{array}\right\}$ & $\cdots$ & $\cdots$ & $7793^{\circ} \mathrm{O}$ & $\cdots$ & $\ldots$ & 0.63 \\
\hline $\left.\begin{array}{l}30952 \cdot 1 \\
38744 \cdot 8\end{array}\right\}$ & $\cdots$ & $\cdots$ & $7792 \cdot 7$ & $\cdots$ & $\cdots$ & 0.7 \\
\hline $\left.\begin{array}{l}33569 \cdot 4 \\
41365 \cdot 1\end{array}\right\}$ & $\cdots$ & $\cdots$ & $7795^{\circ} 7$ & $\cdots$ & $\ldots$ & 490 \\
\hline $\left.\begin{array}{l}34217.7 \\
42010 \cdot 2\}\end{array}\right\}$ & $\cdots$ & $\cdots$ & $7792 \cdot 5$ & $\ldots$ & $\ldots$ & 0.9 \\
\hline $\left.\begin{array}{l}34526 \cdot 2 \\
42321 \cdot 4\end{array}\right\}$ & $\cdots$ & $\cdots$ & $7795^{\circ} 2$ & $\cdots$ & $\cdots$ & $4^{\circ} 5^{\circ}$ \\
\hline $\left.\begin{array}{l}35372 \cdot 1 \\
43164 \cdot 7\end{array}\right\}$ & $\cdots$ & $\cdots$ & $7792 \cdot 6$ & $\cdots$ & $\ldots$ & $I \cdot 20$ \\
\hline $\left.\begin{array}{l}36879^{\circ} 2 \\
44671^{\circ} 0\end{array}\right\}$ & $\cdots$ & $\cdots$ & $7791 \cdot 8$ & $\ldots$ & $\cdots$ & 240 \\
\hline $\begin{array}{l}375^{\circ} 3^{\circ} \circ \\
45^{2} 93^{\circ}\end{array}$ & $\cdots$ & $\ldots$ & 7790.8 & $\ldots$ & $\ldots$ & $2^{\circ}$ \\
\hline $\left.\begin{array}{l}38305^{\circ} \circ \\
46096 \cdot 8\end{array}\right\}$ & $\cdots$ & $\cdots$ & $7791 \cdot 8$ & $\cdots$ & $\cdots$ & $6 \cdot 80$ \\
\hline $\left.\begin{array}{l}38663 \cdot 3 \\
4645^{2} \cdot 4\end{array}\right\}$ & $\cdots$ & $\cdots$ & $7789^{\circ} \mathrm{I}$ & $\cdots$ & $\cdots$ & $7: 30$ \\
\hline $\left.\begin{array}{l}39157^{\circ} \circ \\
46947^{\circ} 3\end{array}\right\}$ & $\cdots$ & $\cdots$ & $7790^{\circ} 3$ & $\cdots$ & $\ldots$ & 8.20 \\
\hline
\end{tabular}

The mean of the twelve differences, assuming their weights to be inversely proportional to the square of the estimated limit of error, is $7792^{\circ}$. When the wavelengths are not reduced to vacuo, the differences are also very nearly constant, because the reduction alters them all nearly by the same amount. But it was a source of satisfaction to me, that the reduction brought all the deviations from the mean value well within the limits of error, whereas without the reduction the second difference had been just beyond the limit. These twelve doublets do not comprise half the number of wave-lengths that have been

NO. I 335 , VOL. 52] 
observed in the spectrum of thallium. But, nevertheless, I think any one will agree that their numerical relation is no chance coincidence. Let us now make a drawing of these doublets to the scale of $\mathrm{I} / \lambda$. Evidently the twelve first lines will give the same picture as the twelve second lines. Let us therefore, to simplify matters, only plot down the twelve first lines. At first glance this does not show any remarkable regularity; but if we drop the fourth and sixth line, we can arrange the rest in two series, as is shown in Fig. I, both rows resembling the series of lines in the spectrum of hydrogen, which are so accurately represented by Balmer's formula. Recurring now to the general list of lines observed in the spectrum of thallium, we find that all five lines of the first series are accompanied on their more refrangible side by strong and easily reversed lines, while the lines of the second series are single. Thus not only does the symmetry of the drawing justify the separation of the lines into two series, but their that only four lines out of sixty do not show any signs of a system according to which they are grouped.

I have given this detailed account of the arc spectrum of thallium only as an example; for I might describe many more spectra that show a similar regularity in the distribution of many of their lines. But there is another interesting point. The distribution of lines in the spectra of chemically related elements shows evident signs of a common plan. I will, for instance, describe the series of triplets in the spectra of magnesium, calcium, and strontium.

The most prominent lines in the visible spectrum of magnesium are the three green lines 5184, 5173, 5168 $10^{-8} \mathrm{~cm}$. forming the group $b$ in the solar spectrum. In the ultra-violet, at least ten repetitions of this group have been observed, two more being doubtful on account of their weakness and nebulosity. The differences of wavenumbers have been found to be the same in all the groups,

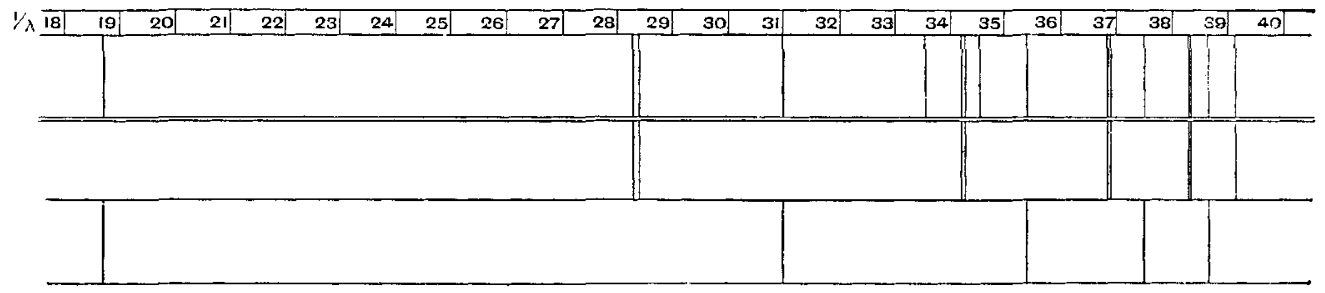

FIG. $x$.

appearance teaches us the same. We may expect to find that a formula similar to that of Balmer connects the lines of each of these two series. Indeed, for suitable values of $\mathrm{A}, \mathrm{B}, \mathrm{C}$ the wave-numbers may be calculated from the formula,

$$
\mathrm{A}-\mathrm{B} n^{-2}-\mathrm{C} n^{-4}
$$

$A$ and $B$ having nearly the same values for both series, and $n$ assuming the values $4,5,6,7,8$ for the first, and $3,4,5,6,7$ for the second series. One may state the formula thus : if the wave-numbers be plotted as ordinates to the abscissæ $1 / 3^{2}, 1 / 4^{2}, 1 / 5^{2}$, \&c., the points form a parabola. If we now go on substituting for $n$ the subsequent whole numbers, we find that all these calculated wave-lengths really exist in the spectrum. But they are weaker and weaker for higher values of $n$. Prof. Kayser and I have been able to observe the wave-lengths calculated by the formula of the first series for $n=9$, IO, II, I 2, I3, $14,15,16$, and by the formula of the second for $n=8,9$, IO, I I, I 2, I 3, I 4, I 5. We searched for the second members corresponding to these lines, but could not detect them, owing to our plates not being sensitive enough for wavelengths as small as $2 \mathrm{I} 00$. However, they have nearly all been observed by Cornu. If we accept Cornu's wavelengths, we now have two series of doublets of equal width in the scale of wave-numbers, and a drawing of them shows a remarkable symmetry (Fig. 2). The drawing comprises 47 out of 60 lines that constitute the arc spectrum of thallium, including Cornu's observations. Of the thirteen lines left, five are the strong lines, mentioned above, that accompany the five first lines of the first series on their more refrangible side. The distance between each line and its companion grows smaller as we advance to smaller wave-lengths, the last distance being not more than $0^{\circ} 45$ $10^{-8} \mathrm{~cm}$. It seems probable that the next lines also have their companions, which, however, so closely coincide with them that it has not been possible to separate them. So there are only eight lines left, the positions of which do not enter into the general plan of the spectrum. Among these eight lines there are two doublets of the same difference of wave-numbers as all the other doublets. Both widen asymmetrically--one towards the more refrangible side, the other to the less refrangible side. Thus we may say as may be seen from the following list. The wave-lengths have not been reduced to vacuo, because all three lines of one group are so near one another that they would all be changed by nearly the same amount, so that the differences of wave-numbers would practically remain the same.

\begin{tabular}{|c|c|c|c|c|}
\hline$\lambda$ & & & $I / \lambda$ & Difference \\
\hline $5183 \cdot 84$ & $\cdots$ & $\ldots$ & $19290 \% 7$ & \\
\hline $5172 \cdot 87$ & $\ldots$ & $\ldots$ & $1933^{1} 6$ & $\begin{array}{l}409 \\
19.9\end{array}$ \\
\hline $5167 \cdot 55$ & $\cdots$ & $\cdots$ & $1935^{\circ} 5$ & \\
\hline $3^{8} 3^{8} \cdot 44$ & $\cdots$ & $\ldots$ & $26052 \cdot 2$ & \\
\hline $3832 \cdot 46$ & $\ldots$ & $\ldots$ & $26092 \cdot 9$ & $40 \%$ \\
\hline $3^{829} 9^{\circ} \mathrm{I}$ & $\cdots$ & $\cdots$ & $26113^{\circ} 0$ & \\
\hline $3336 \cdot 83$ & $\ldots$ & $\ldots$ & $29968 \cdot 6$ & \\
\hline $3332 \cdot 28$ & $\cdots$ & $\cdots$ & $30009 \cdot 5$ & 19.8 \\
\hline $3330^{\circ} 08$ & $\ldots$ & $\ldots$ & $3^{0029^{\circ}} 3$ & \\
\hline $3097^{\circ} 06$ & $\ldots$ & $\ldots$ & $32288 \cdot 7$ & \\
\hline $3093 \cdot 14$ & $\cdots$ & $\cdots$ & $32329^{\circ} 6$ & 20.5 \\
\hline $3095 \cdot 18$ & $\cdots$ & $\cdots$ & $3235^{\circ} \mathrm{I}$ & \\
\hline $2942 \cdot 21$ & $\ldots$ & $\ldots$ & $33988 \cdot \mathrm{I}$ & \\
\hline $2938 \cdot 67$ & $\cdots$ & $\cdots$ & $34029^{\circ} \circ$ & $\begin{array}{l}40.9 \\
19.5\end{array}$ \\
\hline $2936^{\circ} 99$ & $\ldots$ & $\cdots$ & $34048 \cdot 5$ & \\
\hline $2848 \cdot 53$ & $\ldots$ & $\ldots$ & $35^{105} \cdot 8$ & 20 \\
\hline $2846^{\circ} 9 \mathrm{I}$ & $\ldots$ & $\ldots$ & $35125 \cdot 8$ & \\
\hline $2781 \cdot 53$ & $\cdots$ & $\cdots$ & $3595^{\circ} 4$ & $4 I^{\prime} \mathrm{I}$ \\
\hline $\begin{array}{l}2778.36 \\
2776.80\end{array}$ & $\begin{array}{l}\cdots \\
\ldots\end{array}$ & $\begin{array}{l}\cdots \\
\ldots\end{array}$ & $\begin{array}{l}35992 \cdot 5 \\
36012 \cdot 7\end{array}$ & $20 \cdot 2$ \\
\hline $2736 \cdot 84$ & $\ldots$ & $\ldots$ & $36538 \cdot 5$ & \\
\hline 2733.80 & $\ldots$ & $\ldots$ & $36579^{\circ} \mathrm{I}$ & 40.6 \\
\hline $273^{2} \cdot 35$ & $\cdots$ & $\cdots$ & $36598 \cdot 5$ & \\
\hline $2698 \cdot 44$ & $\cdots$ & $\ldots$ & $3705^{8} \cdot 4$ & $40^{\circ} 1$ \\
\hline $2695 \cdot 53$ & $\ldots$ & $\cdots$ & $37098 \cdot 5$ & 21.4 \\
\hline $2693^{\circ} 97$ & $\ldots$ & $\cdots$ & $37+19^{\circ} 9$ & \\
\hline $2672^{\circ} 90$ & $\ldots$ & $\cdots$ & $37412 \cdot 6$ & $42 \cdot 8$ \\
\hline $2669 \cdot 84$ & $\ldots$ & $\cdots$ & $37455^{\circ} 4$ & $22 \cdot 2$ \\
\hline & $\cdots$ & $\cdots$ & $37477^{\circ} 6$ & \\
\hline $2649^{\circ} 3^{\circ}$ & $\cdots$ & $\cdots$ & $37745^{\circ}$ & $3^{8 \cdot 4}$ \\
\hline 2646 & 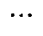 & $\cdots$ & $37784^{\circ} 2$ & $19 \cdot 8$ \\
\hline $2645^{\circ 22}$ & $\ldots$ & $\cdots$ & $37804^{\circ} \circ$ & \\
\hline
\end{tabular}

In the sixth triplet, the first line has not been observed. There is a very strong line $2852^{\circ} 22$ not far from where the NO. I 335, VOL. 52] 
first line of the triplet should be. But this one is out of the question on account of its enormous energy, which would be quite out of comparison with the other lines. So we must suppose that the first line of the triplet is concealed by the strong line. Indeed, on the plates Prof. Kayser and I have examined, it would be impossible to detect a line close to 2852. Again, as in the spectrum of thallium, these triplets form two series (see Fig. 3), and again we find that the wave-numbers of the first, second, and third lines in each series are very accurately represented by a formula,

$$
\mathrm{A}-\mathrm{B} n^{--}-\mathrm{C} n^{-4}
$$

$n$ standing for the row of entire numbers. For each series there are three values of $A$, but only one value of $B$, and sponding rays have not been identified with certainty. There are many lines beside those forming the triplets. For magnesium, the triplets contain 33 out of 56 lines, for calcium 33 out of 106 , for strontium 29 out of 97 . We have found that, as a rule, the higher the melting point of an element, the greater is the percentage of lines in the arc spectrum that do not belong to the series. From magnesium to calcium, and from-calcium to strontium, the triplets widen and shift to the less refrangible side of the spectrum. The same thing happens in the spectra of other groups of chemically-related elements, the difference of wave-numbers of the doublets or triplets being somewhat proportional to the square of the atomic weight.

There is one more feature which seems interesting in regard to the connection of the spectra of different

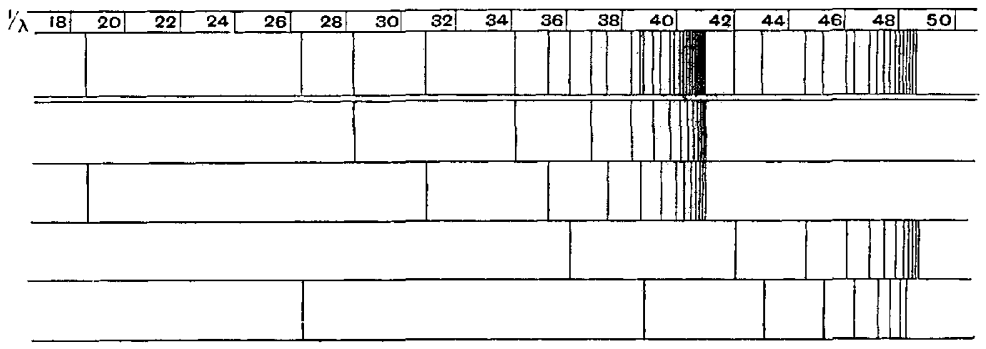

FIG. 2.

one value of $C$. The three values of $A$ are very nearly the same in both series, indicating that the ends of both series coincide. The lowest number for which the formula gives a positive value is $n=3$. To this value corresponds the strong green triplet. But in the other series the corresponding triplet ought to be found near $1300010^{-8}$ $\mathrm{cm}$. where photographic methods fail. It may be that it is identical with the lines that Becquerel has found near I 2000 and I I I2O, the first of which, he says, is possibly double. The deviation between these and the calculated values is not so very great, considering the wide extrapolation of the formula. A small change in the value of C would alter the formula much more for $n=3$ than for the higher values of $n$. Besides, we believe the formula only to be an approximation to the true function which may be developed into a series of descending powers of elements. In all the formula of series that have been observed, the coefficient of $n^{-2}$ does not vary more than about Io per cent. from its mean value, if we except one of the two series of doublets in the spectrum of aluminium where the variation is somewhat larger. . I think, when in some time a satisfactory theoretical explanation of the symmetry in the spectra of the elements will be given, this co-efficient will prove to be an important physical constant.

C. RUNGE.

\section{KARL VOGT.}

THE life of Prof. Karl Vogt, who died on May 6, was no tranquil scientific career, for he was a fighting philosopher. He first comes into notice in 1839 , working with Agassiz, then Professor at Neuchatel, on

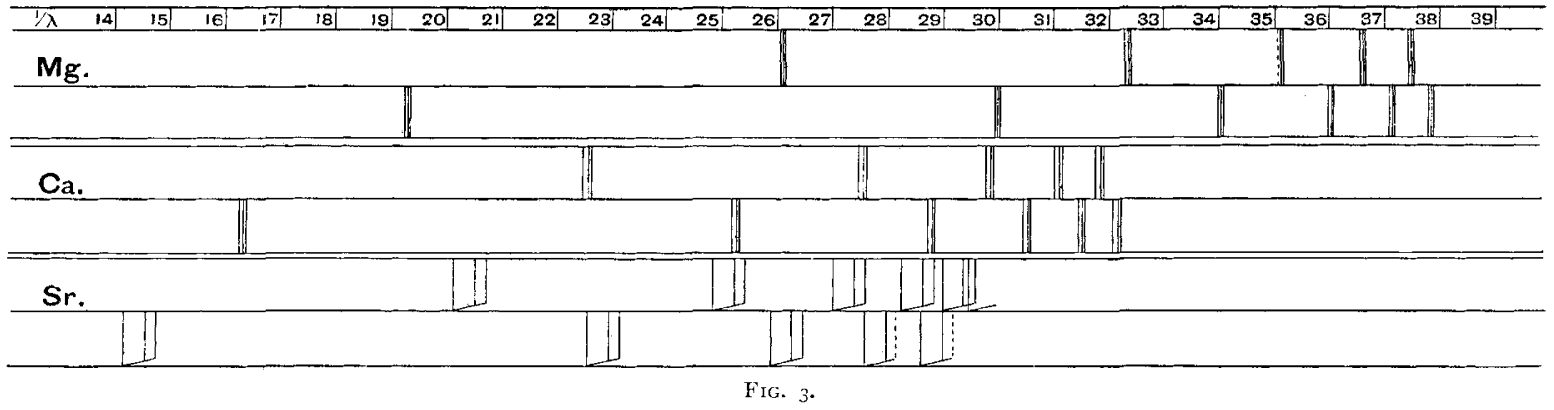

$u^{2}$. If this is so, the neglected terms would affect the values of the formula much more for the low values of $n$, than for the higher ones. The separation of the triplets into two series is not only suggested by the symmetry of the distribution, but also by the aspect of the lines.

In the spectra of calcium and strontium, we also find triplets with the same differences of wave-numbers, and their appearance teaches us in each spectrum to separate them into two series. We then see that the distribution of triplets shows a remarkable similarity to that in the spectrum of magnesium.

The dotted lines in the figure mean that the corre- the "Freshwater Fishes of Central Europe." This great work, never completed, determined the direction of Vogt's best research during the rest of his long life. It was only in I 888-94 that the "Traité d'Anatomie Comparée," by Vogt and Jung, was published in Paris, taking high rank as a standard authority, and likely to retain it. He returned from Paris to his native town of Giessen, where he had been appointed Professor. But the revolution of I 848 soon burst forth, and we hear of him as an advanced Democratic Deputy contending for liberty and progress with the trenchant oratory he could use alike in politics and science Political forces were too strong against him, and 